Literatura y Lingüística $\mathrm{N}^{\circ} 26$

ISSN 0716-5811 / pp. 183-204

\title{
Estrategia pedagógica para la producción textual: casos de desarrollo de conceptos*
}

\author{
Alejandra Leal Ladrón de Guevara**
}

\section{Resumen}

Si bien el aprendizaje de conceptos es común a todas las lenguas, se señala la idea de que la práctica de una propuesta pedagógica centrada en el desarrollo de conceptos mejora la producción textual de los estudiantes de pregrado. Esta exposición tiene el objetivo de describir los cuatro indicadores (SD, SE, SA y $\mathrm{SNE}$ ) con los respectivos descriptores de función, fondo y forma para el dominio de desarrollo del concepto, además, dar a conocer casos de textos elaborados por los estudiantes en la aplicación didáctica. Se concluye que el estudio y ejercicio de la estrategia mejora las habilidades en la producción textual del desarrollo de conceptos.

Palabras clave: Estrategia, secuencia didáctica, desarrollo de concepto.

\section{Pedagogical strategy for text production: concept development cases}

\begin{abstract}
While, learning concepts is common to all the different languages, the idea remains that the implementation of a pedagogical proposal focused on the development of concepts improves textual production in undergraduate students. This work aims to describe four indicators (SD, SE, SA, and SNE) with the corresponding descriptors of function, content and form, for the mastery of concept development; also, it aims to present cases of texts developed by students in the didactic application. The conclusions suggest that study and strategy use improves concept development skills in text production.
\end{abstract}

Key Words: Strategy, didactic sequence, concept development.

Recibido: 05-01-2012 Aceptado: 05-06-2012

* Esta exposición muestra trabajos elaborados por los estudiantes en la "Propuesta metodológica de estrategias didácticas para desarrollar las habilidades de comprensión y producción del desarrollo del concepto en estudiantes de pregrado", realizada en la Universidad Austral de Chile Sede Puerto Montt (DID S-2010-55).

** Doctora en Ciencias Humanas. Universidad Austral de Chile, Sede Puerto Montt, Chile. alejandraleal@spm.uach.cl 
Estrategia pedagógica para la producción textual: casos de desarrollo de conceptos / Alejandra Leal Ladrón de Guevara

\section{Introducción}

Los trabajos exigidos por los docentes en el medio universitario se refieren a los contenidos de textos tales como informes o ensayos, además de los apuntes, resúmenes y exposiciones del profesor, en los cuales se enfatiza acerca de la elaboración epistemológica de la información. En este marco, el texto escrito por el estudiante se descontextualiza de la realidad personal como de su procedencia textual, dirigiéndolo a un destinatario con escasa presencia en el texto, no obstante, éste debe demostrar el dominio de sus competencias comunicativas (Cassany, 2002, 2005; Parodi, 2007, 2008).

Según esta materia, los resultados de las evaluaciones de los estudiantes que ingresan a las aulas universitarias arrojan deficiencia en el dominio de la producción textual. Esto se refleja en las pruebas tanto nacionales del Sistema de Medición de la Calidad de la Educación (SIMCE) y de medición internacional (PISA) sobre los estándares de la calidad en educación de la Organización para la Cooperación y el Desarrollo Económico (Sarramona 2004, Ahumada 2005, Kennedy 2007, Mineduc 2010). Aunque hoy se sigue aspirando a resultados más alentadores, cabe señalar que las estrategias para resolver las nuevas problemáticas que demanda la actividad universitaria son insuficientes para enfrentar el desarrollo de las propuestas de lectura y escritura a las que se adicionan las nuevas tecnologías.

De acuerdo a esto, parece natural que sea el estudiante quien utilice estrategias derivadas de su experiencia para descubrir los 'conceptos clave' en la comprensión y producción de los textos exigidos en su tarea disciplinar. No obstante, el destinatario-docente sí está presente en las evaluaciones de dominio de conceptos a los que, en muchos casos, no se presentan modelos para el análisis y, en consecuencia, tras la producción textual, se proponen respuestas arbitrarias.

\section{Planteamiento del problema}

De acuerdo a lo anterior, cabe preguntarse qué se enseña en lectura y escritura en el pregrado para superar la deficiencia en el dominio de la comprensión y la producción textual y de qué forma se presentan las estrategias para resolver las nuevas problemáticas que demanda la pedagogía en la vida académica. No obstante, el conocimiento del pedagogo puede convertirse en interpersonal en la medida que sus estudiantes compartan una fracción de esos modelos mentales, de

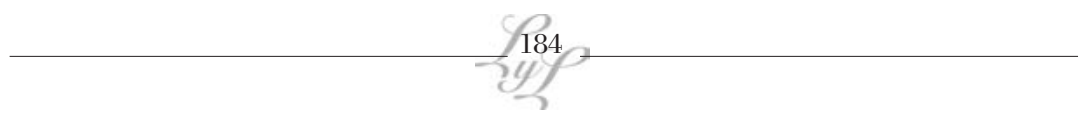


manera que pueda elaborar las inferencias para reconstruir los hechos (Leal, 2009a).

En el contexto de la Educación Superior, el estudiante debe resolver de manera eficaz el problema del saber y del saber hacer en la producción escrita y, a la vez, demostrar el dominio del conocimiento adquirido (Sarramona, 2004). De esto se asume que existe un vacío en la delimitación de una lógica para el desarrollo de un concepto, en la medida que la descripción del objeto es el primer componente de la producción y no las características del objeto, como muy posterior a ello, los argumentos que defienden una tesis, o bien, los ejemplos de transferencia del concepto desarrollado (Leal, 2009a, 2009b, 2010).

\section{Objetivos}

Demostrar que los estudiantes logran un mejor rendimiento en la secuencia lógica del desarrollo del concepto (DC) cuando éste se enmarca en el aprendizaje de un modelo apropiado a los requerimientos de la pedagogía. Esto se complementa con la muestra de casos de textos disciplinares elaborados por los estudiantes, con la descripción del uso de los descriptores de función, fondo y forma en los cuatro indicadores (SA, SE, SA y SNE).

\section{Marco teórico}

\subsection{El concepto}

De acuerdo a las teorías del aprendizaje, un 'concepto' es la representación mental de las categorías de algo, el cual cuenta con características propias, permitiendo su identificación y el acceso a ejemplares afines, o bien, la exclusión de este (Howard, 1987; Schunk, 1997). Por su parte, Ausubel, Novak \& Hanesian (1983) definen los conceptos como "objetos, acontecimientos, situaciones o propiedades que poseen atributos de criterio comunes y que están diseñados en cualquier cultura dada mediante algún signo o símbolo aceptado"; según el objetivo "hacen posible la adquisición de ideas abstractas sin experiencia empírico-concreta: ideas que pueden emplearse para categorizar nuevas situaciones dentro de secciones existentes"; como soporte de nuevos conocimientos y de la función que estos cumplen, "uniforman y simplifican el ambiente y, por consiguiente, facilitan el aprendizaje por recepción, la resolución de problemas y la comunicación". En conformidad a esto, a través de 
Estrategia pedagógica para la producción textual: casos de desarrollo de conceptos / Alejandra Leal Ladrón de Guevara

los conceptos se emplea una de las tantas formas útiles para concretar y especificar la existencia de la cosas (Ausubel, Novak \& Hanesian 1983:88).

\subsection{Las estrategias de análisis y síntesis}

Para aprender un concepto, un hecho, un valor, un principio o una actitud, se utilizan estrategias o modos metacognitivos como el análisis y la síntesis. El 'análisis' obedece a una destreza intelectual de profundización sistemática del conocimiento, aplicable desde lo general a cada una de las partes del objeto de estudio; exige tener claridad acerca de las opiniones y las creencias individuales y grupales, permitiendo tanto el conocimiento de teorías científicas como sociales para establecer relaciones entre otras áreas de la cultura (van Dijk, 2002; Harvey, 2005). En cambio, la 'síntesis' permite identificar los elementos esenciales de un hecho, información, teoría u otra, además, profundizar en lo relevante y transferir el patrón a otras situaciones (Salas, 1995; Carrasco, 2000, 2002; Beas, Santa Cruz, Thomsen, Utreras, 2003; Argudín, 2006; Kennedy, 2007; Villa \& Poblete, 2007; Zabala \& Arnau, 2008). En el marco del diseño de las evaluaciones en donde el estudiante se acerca a los requerimientos de la asignatura, en estrecha relación con los parámetros de aprendizaje propuestos por el docente, el uso de la 'rúbrica' establece niveles o descriptores para cada categoría de la revisión global y analítica, alejando los márgenes de inequidad en la medición del contenido textual (Condemarín \& Medina, 2002; Ahumada, 2005).

\subsection{La secuencia didáctica}

En la medida que los modelos estables del texto se clasifican en 'secuencias': narrativa, descriptiva, argumentativa, explicativa y dialogal; estas se encuentran conformadas por categorías que permiten el reconocimiento de segmentos textuales adaptados al modelo prototípico (Adam, 19871996; López, 2005; Calsamiglia \& Tusón, 1999; Cademartori, 2003; Cassany, 2005). En este sentido, se requiere la transferencia escrita de un 'párrafo semántico' en correspondencia con las partes contenidas en cada secuencia (Roa, 1989; Serafini, 2007). De acuerdo al diseño de la 'secuencia didáctica' para desarrollar cada escrito, se requiere de la composición de una guía de aplicación con "los objetivos, los contenidos, las actividades en un proyecto de trabajo o de producción verbal" (Grau, 2005; Vilá i Santasusana, 2005), además del diseño consensuado de una rúbrica para su revisión durante el proceso como para el trabajo final.

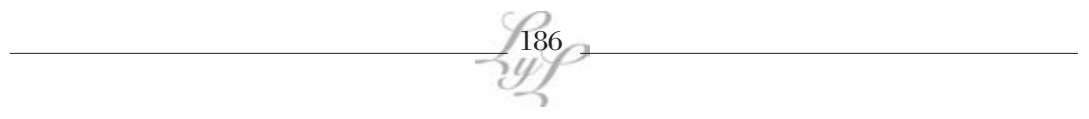




\subsubsection{La secuencia descriptiva (SD)}

Esta secuencia posee la función de detallar el qué y el cómo se constituye el concepto, la idea, el proceso, el estado, el actante, el lugar, además, activa la frecuencia de relaciones conceptuales por sus atribuciones, las características y la especificación de estos. No obstante, cada concepto requiere que los propios atributos sean diferenciados de otros más genéricos, de manera que la jerarquía de rasgos aluda a nuevos conceptos que deben ser aclarados cuando se requiera, así, "los nuevos conceptos o significados conceptuales se engloban bajo otros conceptos más amplios" (Novak, 1997). Además de la función, también se requiere de la composición adecuada en la estructura gramatical (fondo) y otra relativa a la forma, fundamentalmente lógica y jerárquica en la distribución de las ideas.

Como recurso metacognitivo, obedece a una destreza intelectual de profundización sistemática del conocimiento; aplicable desde la idea general a cada una de las partes del objeto del estudio. Al respecto, se destaca el trabajo de M. Cristina Martínez (1997a, 1997b), quien desarrolla el concepto de los prototextos o modelos textuales usados en las ciencias y los textos expositivos (Martínez, 1997b:121).

Además de lo expuesto hasta aquí, leer textos requiere activar el 'conocimiento previo'. Según la teoría constructivista del aprendizaje, los organizadores previos son estrategias que permiten realizar un anclaje entre el conocimiento nuevo y el adquirido. Este se efectúa cuando se contrastan las nuevas ideas con las conocidas, esto es, evaluando y contrastando la relevancia de lo que se lee con las implicaciones personales (Ausubel, Novak \& Hanesian, 1983). De manera que el desarrollo de esta secuencia requiere diferenciar lo sabido con el nuevo conocimiento, construir la idea y transferirla como un nuevo aprendizaje. Véase el siguiente cuadro para esta composición semántica:

\begin{tabular}{|l|l|l|}
\hline \multicolumn{1}{|c|}{ FUNCIÓN } & \multicolumn{1}{|c|}{ FONDO } & \multicolumn{1}{c|}{ FORMA } \\
\hline Se expresa correctamente & Se expresa clara y & Se evidencia perfección \\
la idea organizadora del & correctamente la estructura & en el escrito con jerarquía \\
concepto (qué); detalla la & gramatical: & espacial de las ideas: de lo \\
conformación del concepto & Usa frases calificativas & general a lo concreto. \\
(cómo). & y adjetivos; posición y \\
& concordancia morfológica. & \\
\hline
\end{tabular}

\subsubsection{La secuencia explicativa (SE)}

Según la manera cómo se comprenden y analizan los conceptos, esta secuencia exhibe el tema para hacerlo conocido y su función consiste 
Estrategia pedagógica para la producción textual: casos de desarrollo de conceptos / Alejandra Leal Ladrón de Guevara

en construir la representación conceptual. Entre las características gramaticales, se encuentran las oraciones subordinadas (causales, consecutivas y finales), el empleo de conectores (de causa, consecuencia, etc.); la estructura de esta parte del desarrollo del concepto es lógica y jerárquica, así también, analítica. Como estrategia de análisis, permite asimilar la composición mediante procedimientos que involucran el conjunto reordenado de los elementos en acciones afines y de asociaciones internas (Salas 1995, Acosta 2002, Villa \& Poblete 2007). De igual modo, siendo una destreza intelectual, la síntesis permite identificar los elementos esenciales del concepto, además de profundizar en lo relevante del contenido, pudiéndose transferir este patrón a otras situaciones de estudio en donde se obtienen nuevos conocimientos. Véase el cuadro para esta composición semántica:

\begin{tabular}{|c|c|c|}
\hline FUNCIÓN & FONDO & FORMA \\
\hline $\begin{array}{l}\text { Se analiza, compara, } \\
\text { comprende e interpreta } \\
\text { correctamente el concepto; } \\
\text { se descompone la } \\
\text { representación conceptual. }\end{array}$ & $\begin{array}{l}\text { Se emplean correctamente } \\
\text { las oraciones subordinadas } \\
\text { y sus conexiones: causales, } \\
\text { consecutivas, comparativas } \\
\text { y finales. }\end{array}$ & $\begin{array}{l}\text { Se evidencia corrección } \\
\text { en el desarrollo del } \\
\text { tema: analítica, lógica y } \\
\text { jerárquica. }\end{array}$ \\
\hline
\end{tabular}

\subsubsection{La secuencia argumentativa (SA)}

Esta requiere activar la reflexión en torno a las ideas que refuerzan la validez del concepto y el pensamiento crítico. Al respecto, John Austin (1962) contrapone las expresiones realizativas a las descriptivas (constatativas), expresando que las primeras declaran condiciones para que sean realizadas como proposiciones verdaderas o felices. El pensamiento crítico se realiza cuando se evalúa la relevancia de lo que se lee, se reconoce la verdad del contenido y se identifican las implicaciones ocultas del autor. Sin limitarse al contenido, se ocupa de justificar el porqué de ciertas premisas; por consiguiente, es reflexiva y exige un buen conocimiento del tema tratado (Carrasco, 2002).

De acuerdo a esto, el autor del escrito aspira a convencer al lector de una creencia u opinión (tesis), entregando un conjunto de razones a favor (los argumentos), propone la conclusión. También puede referir ejemplos para apoyar el mismo razonamiento. Lo anterior considera algunos conectores específicos para aclarar el curso de las ideas en cada una de las partes de la argumentación. En la 'premisa' se emplean conectores como: (dado que, desde, por, porque, en razón de que, en vista del hecho de que, asumiendo que, supuesto que, se infiere del hecho de que, puede deducirse que, como es mostrado por, como es

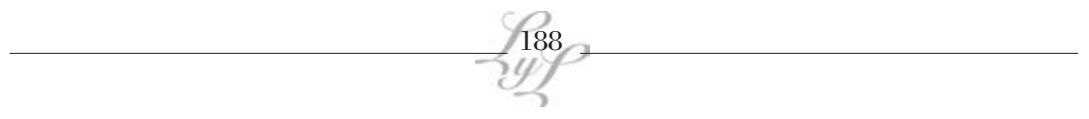


indicado por, como es sustentado por, un dato a favor de, las razones por las cuales, etc.). Para la 'conclusión' (por tanto, consecuentemente, de aquí que, así pues, entonces, implica que, supone que, lo cual muestra que, prueba que, indica que, nos permite concluir que, se deduce que, sugiere que, lleva a creer que, apoya la idea de que, de lo que se sigue que, por lo tanto, como consecuencia de, por consiguiente, por ello, como conclusión...). Un ejemplo concreto puede ser: "Los textos académicos son difíciles de comprender, pues suelen entregar la información crítica sin pautas para el lector en formación". La 'tesis' comprende decir que: "Los textos académicos son difíciles de comprender"; la 'premisa': "Los textos académicos suelen entregar la información crítica sin explicitar una pauta de lectura"; el argumento (causal) "suelen entregar la información crítica sin pautas para el lector en formación". Al respecto, una primera "conclusión' dice que: "Los textos académicos son difíciles de comprender" y, una segunda que: "Los textos académicos son difíciles de comprender, a no ser que se entreguen lineamientos para la lectura". En resumen, para redactar correctamente la SA se considera la actitud crítica frente al estudio de las ideas, así como adecuar el esquema argumentativo con un razonamiento centrado en la verdad y dirigido a lograr la adhesión para esas ideas defendidas. De igual forma, identificar un aspecto del concepto traducido a un problema, analizarlo como tal para reformularlo en un par de proposiciones, finalmente, debatirlo. Esto último indica la necesidad de argumentar y refutar en base a teorías u opiniones encontradas para descubrir el enlace con lo real. Para concluir el escrito, conviene considerar la reducción entre las proposiciones para formular el acuerdo o desacuerdo y definir esas nuevas estructuras de la realidad (Perelman, 1989; Pérez \& Vega, 2003; Martínez, 2005). A continuación, véase la síntesis para esta composición semántica:

\begin{tabular}{|c|c|c|}
\hline FUNCIÓN & FONDO & FORMA \\
\hline $\begin{array}{l}\text { Relación dialógica- } \\
\text { comunicativa para } \\
\text { resolver un problema: } \\
\text { convence o persuade. } \\
\text { Evalúa y toma posición } \\
\text { frente a la relación } \\
\text { conceptual: de razón, } \\
\text { de significación, } \\
\text { deóntica (de } \\
\text { obligatoriedad), de } \\
\text { oposición. }\end{array}$ & $\begin{array}{l}\text { Empleo de oraciones } \\
\text { subordinadas adversativas, } \\
\text { causales, consecutivas. Uso de } \\
\text { verbos como: decir, creer, opinar, } \\
\text { etc.; relación activa entre los } \\
\text { agentes de la comunicación. Usa } \\
\text { conectores adversativos como: } \\
\text { mas, pero, sino, aunque, sin } \\
\text { embargo, no obstante; concesivas } \\
\text { (aunque, así, si bien, aun cuando, } \\
\text { cuando, como, siquiera, ya que, a } \\
\text { pesar de que, bien que, mal que). }\end{array}$ & $\begin{array}{l}\text { Se evidencia relación } \\
\text { jerárquica entre la } \\
\text { premisa, la tesis, los } \\
\text { argumentos y la } \\
\text { conclusión. }\end{array}$ \\
\hline
\end{tabular}


Estrategia pedagógica para la producción textual: casos de desarrollo de conceptos / Alejandra Leal Ladrón de Guevara

\subsubsection{Secuencia de transferencia Narrativa/Ejemplificativa $(\mathrm{SN} / \mathrm{E})$}

El desarrollo de esta secuencia no se limita al contenido nuevo en la voz presentada por el autor de un texto, además, requiere: contrastar lo sabido con el nuevo conocimiento, construir ideas propias y transferirlas en un nuevo contexto de aprendizaje. En este sentido, la secuencia final del desarrollo del concepto parte desde el momento en que se captura con éxito el nuevo saber y se aplica como un conocimiento integrado en otros dominios o áreas de interés tanto en la interacción pedagógica como en el contexto de la vida práctica y social, por lo tanto, exige desarrollar y ahondar en el pensamiento crítico. Apoyándose en el conocimiento previo, se contrastan las nuevas ideas con lo que se sabe para evaluar la relevancia de lo que se lee con las implicaciones personales, las experiencias sociales y culturales del usuario de la lengua. Así también, el factor contextual, el que se encuentra alojado en la experiencia del usuario de textos y los recursos estratégicos de comparación entre áreas del conocimiento, agiliza la búsqueda y aporta los recursos para el uso de las habilidades textuales, de género y propiamente discursivas (Ciapuscio, 1994; Calsamiglia \& Tusón, 1999; Montolio, 2000; Parodi, 2008). Pues, la SNE, más que ser un obstáculo para aprender, es un facilitador para adaptarse a los marcos teóricos vigentes en la práctica de la cultura académica.

A partir de aquí, la transferencia no solo es la construcción del significado de lo que se lee y aplica para conocer, además, comprende el desarrollo de la competencia de descontextualizar lo aprendido para atribuirle nuevos significados. De manera que el estudiante demuestra su competencia global al transferir esta habilidad y ampliar su conocimiento. En suma, se requiere sintetizar estas secuencias previas y organizar una nueva idea-concepto con los atributos del anterior y, de manera complementaria, evidenciar las acciones y los acontecimientos previos, idealmente, en un orden extra contexto y extra discurso.

Tanto las acciones como los acontecimientos se ven reflejados en una 'trama'. Para el propósito de delinear la estructura teórica del desarrollo del concepto, se adecua la definición de trama desarrollada por Tomachevsky (1970) señalada como "el conjunto de acontecimientos considerados en sucesión cronológica y en sus relaciones de causa a efecto" (Hozven 1979). De acuerdo a las relaciones de causa - efecto, es útil aclarar la diferencia de la 'temporalidad y causalidad', dado que se asigna el valor de la causalidad a una relación proposicional de

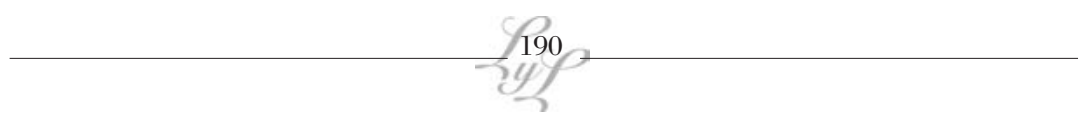


temporalidad. Como se muestra en el siguiente ejemplo, los elementos gramaticales del enunciado verifican el significado de la oración principal y, las complementarias, expresan la causa, razón o motivo de la oración principal: "Lo agasajaron, ya que había desarrollado una brillante labor de relaciones humanas en su trabajo". No obstante, el efecto también es visto desde la estructura gramatical como consecuencia, en la medida que un juicio es consecuencia de otro juicio: "Gasta más de lo que tiene; por consiguiente, no tardará mucho en hundirse económicamente".

De esta forma el estudiante que desarrolla un concepto, aparte de desarrollar la habilidad de 'narrar', además, agrega otras competencias como la de 'ejemplificar' en el desarrollo de su texto con correctas relaciones conceptuales de causa, razón, propósito, posibilidad y proximidad temporal. Esto amerita el empleo de la relación de tiempos verbales, adverbios de tiempo, lugar, espacio, etc. En cuanto a la forma, se expresa cronología en la transferencia: narración - nudo y desenlace de ideas. Se introducen comparaciones de los nuevos conceptos; la acción describe qué y cómo es la estructura conceptual, finalmente, la conclusión refleja un razonamiento lógico y jerárquico de las ideas.

Véase el cuadro con la síntesis para esta composición semántica:

\begin{tabular}{|c|c|c|}
\hline FUNCIÓN & FONDO & FORMA \\
\hline $\begin{array}{l}\text { Se sintetiza, transfiere y } \\
\text { organiza el concepto; el } \\
\text { entramado de las acciones } \\
\text { y los acontecimientos se } \\
\text { dan en un orden extra } \\
\text { contexto y extra discurso. } \\
\text { Empleo de situaciones } \\
\text { nuevas indicando qué, } \\
\text { quién, cómo, cuándo, } \\
\text { dónde. }\end{array}$ & $\begin{array}{l}\text { Se realizan relaciones } \\
\text { conceptuales de causa, } \\
\text { razón, propósito, } \\
\text { posibilidad y proximidad } \\
\text { temporal; se usa la } \\
\text { relación de tiempos } \\
\text { verbales, adverbios de } \\
\text { tiempo, lugar, espacio, etc. }\end{array}$ & $\begin{array}{l}\text { Se expresa cronología en } \\
\text { la transferencia: narración, } \\
\text { nudoy desenlace deideas. Se } \\
\text { introducen comparaciones } \\
\text { de los nuevos conceptos; la } \\
\text { acción describe qué y cómo } \\
\text { es; la conclusión refleja } \\
\text { un razonamiento lógico y } \\
\text { jerárquico. }\end{array}$ \\
\hline
\end{tabular}

\section{Muestra de desarrollo de conceptos}

\subsection{Muestra del texto 'La digestión de los triglicéridos'}

Considerando la propuesta metodológica para desarrollar conceptos, se exhiben dos casos de asimilación de la estrategia. El siguiente texto 'La digestión de los triglicéridos' corresponde al trabajo desarrollado por una estudiante que inicialmente entrelazó solo los indicadores de la descripción y la explicación para desarrollar un concepto. Luego de 
Estrategia pedagógica para la producción textual: casos de desarrollo de conceptos / Alejandra Leal Ladrón de Guevara

ser instruida en la estrategia de DC, construye un indicador en cada párrafo semántico, jerarquizando las ideas desde la SD hasta la SNE. Primera muestra:

Los triglicéridos, o más bien conocidos como grasas, proceden de tres orígenes principales: la alimentación, la biosíntesis de novo del hígado y las reservas existentes en los adipositos (células que guardan grasa). El principal problema al que deben enfrentarse los animales en la digestión es la absorción y transporte de los lípidos que proceden del primer origen mencionado, la insolubilidad de dichas sustancias en medios acuosos, tales como el agua contenida en el organismo. La función de las sales biliares, detergentes sintetizados en el hígado y almacenados en la vesícula biliar, es esencial para la digestión de los lípidos y su absorción a través de la mucosa intestinal. El conflicto que presenta el transporte por la sangre y la linfa se supera en su mayoría con la formación de complejos lipídicos con proteínas que permiten la formación de agregados hidrofílicos, es decir, que son solubles. Estos complejos se denominan hipoproteínas.

Los productos de la digestión de los ácidos grasos comprenden una mezcla formada por glicerol, grasas libres (no unidas a moléculas), mono acilgliseroles. Durante la absorción hecha a través de las células de la mucosa intestinal, se produce la síntesis de triglicéridos a partir de las moléculas resultantes de las hidrólisis. Este proceso tiene lugar en el retículo endoplasmático y en el complejo de Golgi de las células de la mucosa. Los triglicéridos terminan su trayecto en el sistema linfático, formando complejos con proteínas para formar un subtipo de lipoproteínas llamados quilomicrones. Estas moléculas comprenden una gota de aceite recubierta por lípidos, además de una capa externa de proteínas que contribuye a dispensar y solubilizar una parte de la grasa total para su transporte hacia los diversos tejidos que conforman el organismo. Además, el quilomicrón es un importante transformador del colesterol recolectado en la alimentación.

Sin embargo, este transporte de los ácidos grasos hacia los lugares de reserva debe ser controlado, como todo proceso biológico, y éste en particular no cuenta con puntos de control que certifiquen que las etapas se estén desarrollando correctamente. Todo aquello que aparece en el cuerpo procedente de los alimentos que ingerimos se absorbe, y la mayor parte se transporta hacia el tejido adiposo, más bien, hacia sus células, los adipositos, que son los

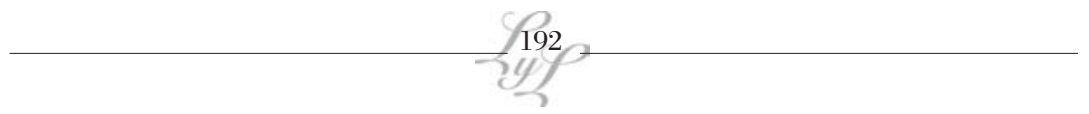


encargados de almacenar las grasas. El problema, no obstante, radica en que consumimos más de lo que requerimos al día para un buen funcionamiento y mantenimiento de los órganos y el sistema en general, lo que, sumado a los pésimos hábitos alimenticios que hemos adquirido en los últimos años como sociedad, se traduce en una patología que se ha hecho muy común: la obesidad. Es por esta razón que se debe mantener una dieta balanceada; alimentarse sanamente, eso sí, no implica privarse de azúcares, sino que más bien, requiere incorporar todos los tipos de alimentos en una cantidad necesaria para los requerimientos nutricionales y energéticos diarios de nuestro organismo.

Una situación similar viven cada invierno los osos, ya que ellos deben aprovisionarse de alimentos durante el invierno y el otoño para mantener buenas reservas de grasa que les permitan mantenerse vivos, puesto que es en estas épocas cuando se disponen a hibernar, algo así como dormir muchos meses seguidos. Por lo tanto, es imprescindible para ellos que el alimento de triglicéridos permanezca inalterable durante todo este período. Esta grasa acumulada les sirve también de abrigo, ya que generan grasa parda, la que en los seres humanos sólo generamos en la niñez. De todas maneras, una vez que el oso despierta de su largo sueño, se dispone a eliminar la acumulación de ácidos grasos con sus actividades habituales como son la caza, trepar árboles y defender a sus crías de las amenazas del ambiente, que no les significa un alto gasto energético, lo que contribuye también al fortalecimiento de los músculos, los huesos y una movilidad adecuada de las extremidades y las articulaciones. (Texto autorizado por Karina Constanza Vera Latorre. Estudiante de Tecnología Médica, promoción 2010).

\subsubsection{Análisis textual de 'La digestión de los triglicéridos'}

5.1.1.1. Desarrollo del indicador SD. En el primer párrafo semántico, la estudiante expone el indicador SD, iniciando la construcción de la idea organizadora del concepto (qué) para el descriptor de función. Aunque la concordancia gramatical con el descriptor de fondo amerite una primera oración, la idea se expresa en la segunda [El principal problema al que deben enfrentarse los animales en la digestión es la absorción y transporte de los lípidos]. Esta se complementa con la primera oración [proceden de tres orígenes principales: la alimentación, la biosíntesis de novo del hígado y las reservas existentes en los adipositos (células que guardan 
Estrategia pedagógica para la producción textual: casos de desarrollo de conceptos / Alejandra Leal Ladrón de Guevara

grasa)]. Posteriormente, se detalla la conformación del concepto (cómo), con los atributos y características de la existencia de la 'digestión de los triglicéridos', tal como [...insolubilidad de dichas sustancias en medios acuosos... en el organismo... las sales biliares, detergentes sintetizados en el hígado y la vesícula biliar... y su absorción a través de la mucosa intestinal]. Otra idea es [El conflicto que presenta el transporte por la sangre y la linfa], superado por la formación de [complejos lipídicos... hipoproteínas]. En suma, la descripción del proceso se enmarca en el escrito del primer párrafo asignando jerarquía de las ideas.

5.1.1.2. Desarrollo del indicador SE. En la medida que el problema está en el transporte, el segundo párrafo semántico desarrolla la idea explicativa de este proceso de absorción. Esto sigue con la descomposición [Los productos de la digestión de los ácidos grasos comprenden glicerol, grasas libres (no unidas a moléculas), mono acilgliseroles]. En el detalle del fondo gramatical del párrafo se componen oraciones simples y compuestas, como se explicita en una oración gramatical consecutiva: [Durante la absorción hecha a través de las células de la mucosa intestinal, / se produce la síntesis de triglicéridos a partir de las moléculas resultantes de las hidrólisis]. Posteriormente, se especifica [Este proceso tiene lugar en el retículo endoplasmático y en el complejo de Golgi de las células de la mucosa]. Sigue otra oración subordinada modal [Los triglicéridos terminan su trayecto en el sistema linfático, / formando complejos con proteínas para formar un subtipo de lipoproteínas llamados quilomicrones]. En el descriptor de fondo, independientemente de la complejidad del tema, la información se expresa claramente, aunque requiriendo ajustes gramaticales. Finalmente, en el descriptor de la forma, se evidencia perfección en la jerarquía espacial de las ideas principales y las subordinaciones cuando es necesario.

5.1.1.3. Desarrollo del indicador SA. Este tercer párrafo semántico se inicia con la presentación del problema, inducido por un conector adversativo: [Sin embargo,/ este transporte de los ácidos grasos hacia los lugares de reserva debe ser controlado, como todo proceso biológico, y éste en particular no cuenta con puntos de control que certifiquen que las etapas se estén desarrollando correctamente]. A esto sigue la tesis: [Todo aquello que aparece en el cuerpo procedente de los alimentos que ingerimos se absorbe, y la mayor parte se transporta hacia el tejido adiposo, más bien, hacia sus células, los adipositos, que son los encargados de almacenar las grasas].

El argumento que refuerza esta relación entre la tesis y las bases (premisas) contenidas en la costumbre alimenticia se lee como sigue:

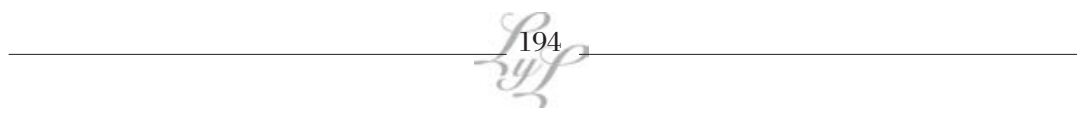


[El problema, no obstante, radica en que consumimos más de lo que requerimos al día para un buen funcionamiento y mantenimiento de los órganos y el sistema en general, lo que, sumado a los pésimos hábitos alimenticios que hemos adquirido en los últimos años como sociedad, se traduce en una patología que se ha hecho muy común: la obesidad]. Finalmente, en la conclusión planteada se observa: [Es por esta razón que se debe mantener una dieta balanceada; alimentarse sanamente, eso sí, no implica privarse de azúcares, sino que más bien, requiere incorporar todos los tipos de alimentos en una cantidad necesaria para los requerimientos nutricionales y energéticos diarios de nuestro organismo]. En suma, el escrito expresa pertinencia en el uso de los descriptores de la función, el fondo y la forma y se relaciona jerárquicamente el problema, la tesis, el argumento base y la conclusión de la secuencia.

5.1.1.4. Desarrollo del indicador SNE. En el último párrafo semántico se dirá que se transfiere la información de la función y la organización de las acciones en otro contexto, construyendo un nuevo discurso que es asimilado conceptualmente por la idea de la 'digestión de los triglicéridos'. Esto es decir que, al inicio del párrafo, se compara la función de los triglicéridos en el contexto específico de la vida de los osos, revelando la transferencia de la aplicación del concepto: [Una situación similar viven cada invierno los osos]. Luego se explica este proceso en una breve narración explicativa que conecta una trama correspondiente a la acción de la vida particular de este animal: [ya que ellos deben aprovisionarse de alimentos durante el invierno y el otoño para mantener buenas reservas de grasa que les permitan mantenerse vivos, puesto que es en estas épocas cuando se disponen a hibernar, algo así como dormir muchos meses seguidos].

A continuación, se procede a la comparación de contraste conceptual centrada en el proceso de la 'digestión de los triglicéridos': [Por lo tanto, es imprescindible...triglicéridos permanezca inalterable durante todo este período. Esta grasa acumulada les sirve también de abrigo, ya que generan grasa parda, la que en los seres humanos sólo generamos en la niñez]. Enseguida, la comparación de contraste llega a un punto de relación común para ambas ideas de la digestión: [... De todas maneras, una vez que el oso despierta de su largo sueño, se dispone a eliminar la acumulación de ácidos grasos con sus actividades habituales como son la caza, trepar árboles y defender a sus crías de las amenazas del ambiente, que no les significa un alto gasto energético, lo que contribuye también al fortalecimiento de los músculos, los huesos y una movilidad adecuada de las extremidades y las articulaciones]. 
Estrategia pedagógica para la producción textual: casos de desarrollo de conceptos / Alejandra Leal Ladrón de Guevara

En suma, el escrito sintetiza las acciones y los acontecimientos del contexto conceptual, adecuando la transferencia de las ideas de la narración en un caso de digestión específica de los osos, mediante el uso y contribución de las proteínas en el cuerpo del animal. Así, también, el descriptor de 'fondo' se visualiza mediante las correctas relaciones conceptuales de causa, razón, propósito de los hechos y especificidad de los tiempos verbales. La transferencia de las ideas indica una trama con sentido de causalidad, específicamente en el desenlace de la idea de la digestión. Finalmente, en las conclusiones, se refleja un razonamiento lógico y jerárquico de estas ideas.

\subsection{Muestra del texto 'Los virus informáticos'}

En el siguiente caso se muestra el desarrollo del concepto 'Los virus informáticos', correspondiente a un estudiante de la especialidad de Ing. en Computación, quien, luego de recibir la instrucción en la estrategia de DC, enlaza un indicador en cada párrafo semántico, jerarquizando las ideas del concepto. Lectura del texto global:

Los virus informáticos son programas cuyo objetivo es alterar el normal funcionamiento de los computadores sin el conocimiento ni el consentimiento del usuario. Se caracterizan por ser muy nocivos y algunos pueden contener cargas dañinas. Estos tienen básicamente la función de propagarse a través del sistema operativo para el cual fueron creados, actuando más frecuentemente en sistemas basados en Windows que en otras plataformas, como por ejemplo, las derivadas de Unix. Entre los virus más comunes se encuentran los Troyanos, Worms, Retro virus, Bombas lógicas, Hoax y Joke, entre otros.

Por una parte, los Troyanos roban información o alteran el sistema del hardware, permitiendo que un usuario externo tenga acceso a los demás equipos. No así los 'Worms', que se reproducen a sí mismos y cuya finalidad es la de colapsar el sistema. Por otra parte, están los 'Retro virus' que, si bien no atacan directamente al sistema, buscan fallas en los antivirus para así desactivarlos. Sin embargo, existen otros tipos de 'malwares', los cuales se activan al producirse algún evento determinado, como es el caso de las Bombas lógicas, que luego atacan el software del computador de forma directa o indirecta. Finalmente, se encuentran los 'Hoax' y los 'Joke', que, a pesar de no poseer contenidos dañinos, son mensajes molestos que aparecen al realizar un evento determinado y son difíciles de cerrar.

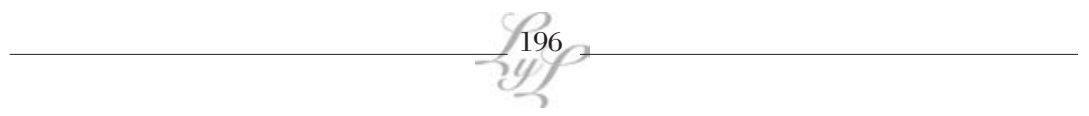


Teniendo todo esto en cuenta, resulta necesario mantener protegidos de estas amenazas a nuestros equipos, además de respetar ciertas normas para el buen funcionamiento del sistema. Para esto, lo más recomendable es tener activado un antivirus que se encargue de defender nuestra computadora de continuos ataques que se filtran a través de la red. Sin embargo, los antivirus que brindan una mejor protección son aquellos que tienen mayores requerimientos, tales como procesadores con mayor rapidez, así como más memoria RAM, o discos duros con mayor capacidad, lo que puede ser visto como un inconveniente al momento de escoger un antivirus que cumpla con los requisitos necesarios para combatir ciertos tipos de virus y se adapte al tipo de computador que se posee.

A pesar de lo anterior, no basta solamente con poseer un buen antivirus, sino que además se debe tener cuidado con los archivos que hay en la red, tanto en páginas de descarga como en correos electrónicos. La razón de esto es porque la mayoría de los virus se almacenan en este tipo de sitios. Se puede tomar como ejemplo el caso del virus 'ILOVEYOU', que fue propagado a través de un correo de Outlook el año 2000, afectando a gran cantidad de computadoras en todo el mundo. Por lo que se concluye de todo lo expuesto que la seguridad informática es un pilar fundamental, ya que siempre habrá amenazas capaces de ocasionar varios problemas los que pueden, incluso, ser de gran importancia para los usuarios. (Concepto autorizado por Alfonso Henríquez. Estudiante de Ingeniería en Computación, promoción UACH, 2010).

\subsubsection{Análisis textual de 'Los virus informáticos'}

5.2.1.1. Desarrollo del indicador SD. En el primer párrafo semántico, el estudiante expone el indicador SD, iniciando la construcción de la idea organizadora del concepto (qué) y el descriptor de función. Aquí incorpora el concepto 'virus informático' en el nombre genérico 'programas' y plantea la función de estos: [Los virus informáticos son programas cuyo objetivo es alterar el normal funcionamiento de los computadores sin el conocimiento ni el consentimiento del usuario]. Posteriormente, enuncia las características [Se caracterizan por ser muy nocivos y algunos pueden contener cargas dañinas]; luego repite la idea de función: [propagarse a través del sistema operativo..., actuando más frecuentemente en sistemas basados en Windows...]. Finalmente los clasifica: [Entre los virus más comunes se encuentran los Troyanos, 
Estrategia pedagógica para la producción textual: casos de desarrollo de conceptos / Alejandra Leal Ladrón de Guevara

Worms, Retro virus, Bombas lógicas, Hoax y Joke, entre otros]. En resumen, el escrito del párrafo presenta una forma jerárquica de las ideas, el qué y cómo se presentan los rasgos desde la función, las características y la clasificación de estos virus.

5.2.1.2. Desarrollo del indicador SE. Por cuanto el 'virus informático' es un programa que afecta al PC, en el segundo párrafo semántico se desarrolla la idea explicativa del proceso de infección, analizando cómo operan. Se emplean los conectores de comparación para contrastar la acción de los virus mencionados y, luego, se interpreta la representación conceptual: [Por una parte, los Troyanos roban información o alteran el sistema del hardware, .... No así los 'Worms',... Por otra parte, están los 'Retro virus' que,... Sin embargo, existen otros tipos de 'malwares', los cuales se activan... Finalmente, se encuentran los 'Hoax' y los 'Joke',... son mensajes molestos]. En suma, los tres descriptores se enlazan armoniosamente en el párrafo.

5.2.1.3. Desarrollo del indicador SA. Este tercer párrafo semántico se inicia con el problema de que los PC no están actualmente protegidos: [Teniendo todo esto en cuenta, / resulta necesario mantener protegidos de estas amenazas a nuestros equipos, además de respetar ciertas normas para el buen funcionamiento del sistema].

A esto sigue la 'tesis' expresada en una propuesta afirmativa: [Para esto, / lo más recomendable es tener activado un antivirus que se encargue de defender nuestra computadora de continuos ataques que se filtran a través de la red].

El argumento que refuerza esta relación entre la tesis y las bases (premisas) está contenido en la protección contra virus informáticos. Esta idea se introduce con el conector adversativo 'sin embargo' de la siguiente manera: [Sin embargo, los antivirus que brindan una mejor protección son aquellos que tienen mayores requerimientos,... procesadores con mayor rapidez, ... memoria RAM, o discos duros con mayor capacidad,... visto como un inconveniente al momento de escoger un antivirus que cumpla con los requisitos necesarios...]. La conclusión se deduce de la tesis y el argumento, un antivirus que [... se adapte al tipo de computador que se posee], puesto que la capacidad del PC aumenta o disminuye la posibilidad de adaptar un antivirus de amplia protección. En síntesis, el indicador evidencia orden, lógica en cada descriptor y jerarquía de las ideas contenidas en la forma de la argumentación.

5.2.1.4. Desarrollo del indicador de SNE. En el último párrafo semántico se dirá que a través del escrito se transfiere la información de la

$+198$


función y la organización de las acciones en otro contexto, construyendo un discurso que amplía el anterior. Se inicia con la introducción de un conector textual [A pesar de lo anterior], que recae en la especificación de que no todos los antivirus 'cumplen con los requisitos', porque el PC no cuenta con la capacidad para instalarlo. En seguida, se propone expandir el tema de los 'virus informáticos' a archivos y páginas de la red [los archivos que hay en la red, tanto en páginas de descarga como en correos electrónicos], como el caso de ['ILOVEYOU'... propagado en Outlook en el 2000]. Con ello, se concluye que el tema queda abierto en la seguridad informática [ya que siempre habrá amenazas capaces de ocasionar varios problemas...].

En conclusión, la transferencia de las ideas se realiza con correctas relaciones conceptuales requeridas para la función; así, también, en la forma en que se usan los tiempos verbales y los conectores se reducen a especificar el ejemplo de la transferencia de los antivirus a escenarios no contemplados (tales como archivos y páginas de la red), lo que facilita su lectura como texto completo.

Con relación al texto anterior, se anexa un segundo trabajo que también elabora el concepto. Esto indica que un mismo concepto puede ser estudiado, analizado y desarrollado con claras diferencias en la distribución de los componentes descriptores al interior de cada indicador, tal como el uso de las alternativas gramaticales y marcado por la diferencia en el estilo de la redacción personal (véase el anexo 2).

\section{Conclusiones}

De lo anterior, se desprende que la aplicación de un programa de actividades didácticas de DC apropiada a las necesidades de los estudiantes, si bien no alcanza a tener un resultado óptimo en el desempeño inicial, es un indicador de apoyo estratégico para avanzar en el estudio de los conceptos disciplinares.

Se plantea que esta herramienta propuesta en secuencias permite al estudiante asimilar de manera gradual cualquier tipo de conocimiento exigido en el aspecto del saber para el saber-hacer durante el proceso pedagógico.

La intervención en la producción de cada secuencia del DC, adaptado a cada área de estudio, permite mejorar el desempeño del estudiante en la comprensión y la producción de los textos. 
Estrategia pedagógica para la producción textual: casos de desarrollo de conceptos / Alejandra Leal Ladrón de Guevara

Se sostiene que esta propuesta pedagógica debe ir acompañada del uso de la rúbrica con los rasgos solicitados al estudiante para alejar los márgenes de inequidad ante las imperantes exigencias del medio académico.

Como conclusión, se expresa que la transferencia didáctica de la producción en los cuatro indicadores (SD, SE, SA, SNE) del DC conforman una propuesta de trabajo en la práctica de la pedagogía de la lengua.

\section{Bibliografía}

Acosta, V. (2002). La evaluación del lenguaje. Granada: Ediciones Aljibe.

Adam, J. (1987). "Types de séquences textuelles élèmentaires”. Practiques No 56. Metz.

(1987). Textualité et séquentialité. L'exemple de la description. Langue francaise, Volume $74, \mathrm{~N}^{\circ} 1,51-72$.

(1992). Lês textes: Types et prototypes. Nathan, Coll. FAC. Paris.

(1996). "(Proto) Tipos: La estructura de la composición en los textos". En Textos de Didáctica de la Lengua y de la Literatura. $\mathrm{N}^{\mathrm{o}} 10,9-22$.

Ahumada, P. (2005). Hacia una evaluación auténtica del aprendizaje. México: Paidós.

Argudín, Y. \& Luna M. (2006). Aprender a pensar leyendo bien. México: Paidós.

Austin, J. (1962). Cómo hacer cosas con palabras. Barcelona: Paidós.

Ausubel, D; Novak, J. \& Hanesian, H. (1983). Psicología educativa: un punto de vista cognitivo. México: Trillas.

Beas, J; Santa Cruz, J; Thomsen, P. \& Utreras, S. (2003). Enseñar a pensar para aprender mejor. Santiago: Ediciones U. Católica de Chile.

Cademartori, Y. (2003). "La inscripción de las personas en textos de divulgación científica ALED”. Revista Latinoamericana de estudios del discurso. Venezuela: Editor Latina. Volumen $3 \mathrm{~N}^{\circ} 1,9-27$.

Calsamiglia H. \& Tusón A. (1999). Las cosas del decir. Barcelona: Ariel.

Carrasco, J. (2000). Cómo aprender mejor. Estrategias de aprendizaje. Madrid. RIALP. (2002). Estrategias de Aprendizaje. Madrid: RIALP.

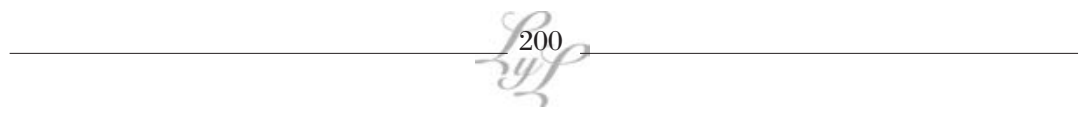


Cassany, D. (2002). La cocina de la escritura. Barcelona: Editorial Anagrama. (2005). "Tipos de textos". Enseñar lengua. Barcelona: Edit. Anagrama.

Condemarín, M. \& Medina, A. (2002). Evaluación auténtica del lenguaje y la comunicación. Madrid: Ciencias de la Educación Preescolar y Especial.

Grau, M. (2005). "La modalización: adecuación del texto a los parámetros de la situación comunicativa". En El discurso oral formal. Contenidos de aprendizaje y Secuencias didácticas. (pp. 77-88). Barcelona: Graó.

Harvey, A. M. (2005). "La evaluación en el discurso de informes escritos por estudiantes universitarios chilenos". Contextos del Discurso. Pilleux, M. (Editor). Valdivia: FRASIS editores. Pp. 215-228.

Hozven, R. (1979). El estructuralismo literario francés. Introducción y Glosario. Santiago: Ediciones del departamento de Estudios Humanísticos, Universidad de Chile.

Howard, R.W. (1987). Concepts and Schemata: An Introduction. Philadelphia: Taylor and Francis.

Kennedy, D. (2007). Redactar y utilizar resultados de aprendizaje. Un manual práctico. Santiago: Ministerio de Educación de Chile. MINEDUC.

Leal, A. (2009a). "Análisis diagnóstico de un problema de escritura en la producción del concepto argumentado". Libro de Actas del II CONGRESO NACIONAL DE LA CÁTEDRA UNESCO LECTURA Y ESCRITURA, 5, 6 y 7 de octubre del 2009. ISBN 978-956-332-461-7. Universidad de Los Lagos, Osorno. Págs. 81-90.

(2009b). "Introducción al discurso pedagógico". Horizontes Educacionales. Chillán: Departamento de Ciencias de la Educación. Facultad de Educación y Humanidades, Universidad del Bío-Bío. Vol. 14, No 1, 51-63.

(2010). "Producción del desarrollo de conceptos: una estrategia de la lengua". Libro de Actas del PRIMER CONGRESO NACIONAL DE PEDAGOGÍA: "Enseñanza de la Lectura de los Textos Pedagógicos y Experiencias en Aula", 3 y 4 de septiembre del 2010. Universidad Austral de Chile Sede Puerto Montt. Págs. 100-110. 
Estrategia pedagógica para la producción textual: casos de desarrollo de conceptos / Alejandra Leal Ladrón de Guevara

López, C. (2005). "¿Qué es un discurso argumentativo razonable? Algunas consideraciones teórico-metodológicas". Discurso y Argumentación. Harvey, A. M. (Compiladora). Santiago de Chile: Ediciones Universidad Católica de Chile. Pp. 33-45.

Martínez, M.C. (1997a). Discurso, proceso y significación. Cali: Universidad del Valle.

(1997b). Análisis del Discurso. Cali: Universidad del Valle.

(2005). La construcción del proceso argumentativo en el discurso. Cali: Universidad del Valle.

Mineduc. (2010). Resultados nacionales SIMCE 2010. Informe de resultados nacionales.Santiago de Chile: Ministerio de Educación. Unidad de Currículum y Evaluación.

Novak, J. \& Gowin, B. (1997). "Mapas conceptuales para el aprendizaje significativo". En: Programa de mejoramiento de la Educación Media. Santiago de Chile: MINEDUC.

Parodi, G. (2007). Lingüística de corpus y discursos especializados: Puntos de mira (Editor). Valparaíso: Pontificia Universidad Católica de Valparaíso.

(2008). Géneros académicos y géneros profesionales: accesos discursivos para saber y hacer (Editor). Valparaíso: Ediciones Universidad Católica de Valparaíso.

Perelman, Ch. \& Olbrechts-Tyteca, L. (1989). Tratado de Argumentación. La Nueva Retórica. Madrid: Gredos.

Pérez, M. \& Vega, O. (2003). Técnicas argumentativas. Santiago: Ediciones U. Católica de Chile.

Roa, A. (1989). Gramática castellana. Santiago: Edit. Salesiana.

Salas, R. (1995). Aprendiendo y enseñando con estilo. Valdivia: Ediciones U. Austral de Chile.

Sarramona, J. (2004). Las competencias básicas en la Educación obligatoria. Ceac: Educación -Actualidad pedagógica. Barcelona: Aleph, Servicios editoriales.

Schunk, D. (1997). Teorías del Aprendizaje. México: Pearson Educación.

Serafini, M. T. (2007). Cómo se escribe. Barcelona: Paidós.

Solé, I. (1996). Estrategias de lectura. Barcelona: Graó. 
Tomachevsky, B. (1979). "Trama”. En Hozven, R. El estructuralismo literario francés. Introducción y Glosario. Santiago: Ediciones del departamento de Estudios Humanísticos, Universidad de Chile. Pág. 168.

Van Dijk., T. (2002). "Tipos de conocimiento en el procesamiento del discurso". En G. Parodi (Editor): Lingüística e interdisciplinariedad: desafios del nuevo milenio. Ensayos en honor a M. Peronard. Valparaíso: U. Católica de Valparaíso. Pp. 41-66.

Villa, A. \& Poblete, M. (2007). Aprendizaje basado en Competencias. Una propuesta para la evaluación de competencias genéricas. Bilbao: Universidad de Deusto.

Vilá i Santasusana, M. et al. (2005). El discurso oral formal. Contenidos de aprendizaje y Secuencias didácticas. Barcelona: Graó.

Zabala, A, \& Arnau, L. (2008). Cómo aprender y enseñar competencias. Barcelona: Graó. 
Estrategia pedagógica para la producción textual: casos de desarrollo de conceptos / Alejandra Leal Ladrón de Guevara

\section{Anexo 1}

Esquema para las actividades de la secuencia didáctica

Objetivo general: aplicar el modelo pedagógico del desarrollo del concepto según la secuencia prototípica (descriptiva) para desarrollar las habilidades de comprensión y producción de esta secuencia del texto académico.

Metodología de trabajo: comprende la presentación de las secuencias didácticas enumeradas según actividades guiadas.

Actividades:

(1). Guía de trabajo textual: Secuencia prototípica (descriptiva), estructura interna del esquema y la unidad compositiva del plan: función, fondo y forma del escrito.

(2). Guía de trabajo. Reconocimiento de la secuencia prototípica.

(3). Guía de trabajo: Reconocimiento y diseño en el marco del desarrollo del concepto. (4). Guía de trabajo: proyecto de producción del desarrollo del concepto en la (secuencia descriptiva)

\section{Anexo 2}

\section{'Virus informáticos'}

Uno de los grandes problemas a los que se enfrentan los usuarios de computadores, es la constante amenaza de virus informáticos. Una breve definición sobre estos 'malwares' nos dice que son programas cuyo principal objetivo es alterar el normal funcionamiento de las computadoras sin el conocimiento previo del usuario. Estos tienen básicamente la función de propagarse a través del sistema operativo para el cual fueron creados, entre los más conocidos encontramos los Troyanos, Worms, Bombas lógicas, Horx, Joke, entre otros. Los Troyanos son los encargados de robar información o alterar el sistema del hardware, permitiendo que un usuario externo tenga acceso a nuestro equipo. A diferencia de los Troyanos. Los 'Worns' tienen el principal objetivo de multiplicarse, provocando así un colapso en el sistema. Sin embargo, existen otros programas dañinos que se activan al generar un evento determinado, como es el caso de las Bombas lógicas, pero también existen otros menos dañinos que lo único que realizan es mostrar imágenes o frases las que molestan al usuario.

Teniendo presente las anteriores definiciones y conociendo los riesgos a los que nuestro PC se encuentra expuesto, es necesario tomar ciertas precauciones, entre la más común se encuentra la instalación de un software antivirus que es el encargado de analizar, detectar y destruir las posibles amenazas a los que nuestro equipo se encuentra expuesto. No obstante, para tener una buena protección se debe cumplir con ciertos requerimientos como la calidad del procesador y la cantidad de memoria RAM, lo que dificulta la selección de buenos antivirus, puesto que estos requieren mejores hardwares.

A pesar de lo anteriormente dicho, no basta solamente con tener una buena protección, sino que debemos ser conscientes y cuidadosos con la gran cantidad de archivos que se encuentra en la red, sobre todo en los documentos o programas de descarga y correos electrónicos. La razón principal se encuentra en programas dañinos que pueden o están anexados a ellos. Un buen ejemplo sobre sus destrozos lo podemos ver en la actualidad en donde un súper virus está afectando plantas industriales en Irán. Esto ha producido grandes colapsos y, además, no se ha podido destruir. Por esto podemos concluir que la seguridad es una prioridad para los usuarios de computadoras, ya que siempre surgirán amenazas, las cuales nos pueden generar desde pequeños hasta graves problemas (Concepto autorizado por Alexis Enoc Oyarzo Velásquez. Estudiante de Ingeniería en Computación, promoción UACH, 2010).

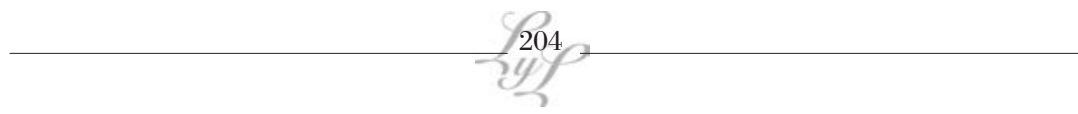

